\title{
Metodologias ativas como espaço de gestão do conhecimento: uma experiência no ensino superior em Comunicação
}

\section{Active methodologies as a space for knowledge management: an experience in higher education in Communication}

\author{
Tamara de Souza Brandão Guaraldo ${ }^{1}$ \\ ${ }^{1}$ Universidade Estadual Paulista (UNESP), São Paulo, SP, Brasil, Brasil. ORCID: https://orcid.org/0000-0001-7925-2021
}

Autor para correspondência/Mail to: Tamara de Souza Brandão Guaraldo, tamara.guaraldo@unesp.br

Recebido/Submitted: 18 de junho de 2021; Aceito/Approved: 31 de julho de 2021

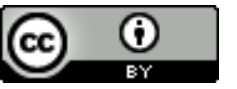

Copyright (C) 2022 Guaraldo. Todo o conteúdo da Revista (incluindo-se instruções, política editorial e modelos) está sob uma licença Creative Commons Atribui-
ção 4.0 Internacional. Ao serem publicados por esta Revista, os artigos são de livre uso em ambientes educacionais, de pesquisa enão comerciais, com atribuição de autoria obrigatória. Mais informações em http://revistas.ufpr.br/atoz/about/submissions\#copyrightNotice.

\begin{abstract}
Resumo
Introdução: No cenário atual do ensino superior na área de Comunicação, é necessária uma formação que amplie a capacitação diante das exigências do mercado. Cresce a necessidade de aliar a teoria à prática no ensino e, com isso, a compreensão do trabalho em equipe e 0 conhecimento da dinâmica de atuação das agências de comunicação. Busca compreender como o uso de metodologias ativas pode criar espaços para a gestão do conhecimento e assim contribuir para a aprendizagem da profissão no contexto disciplinar em cursos de Comunicação. Método: Desenvolve uma pesquisa descritiva de caráter qualitativo aplicada nas turmas em que a autora lecionou em cursos de graduação da área de Comunicação com uso de metodologia da Aprendizagem baseada em projetos e do modelo de cinco fases do processo de criação de conhecimento. Foi aplicada em sala de aula uma dinâmica de formação de agências de comunicação por grupos de estudantes de graduação, no período de 2014 a 2019. Resultados: A mudança do método tradicional para o processo de gestão do conhecimento proposto gerou insegurança e um esforço de interlocução pelos alunos, exigindo maturidade e uma posição de maior autonomia. As agências de comunicação montadas pelos alunos apresentaram a sua identidade e as peças de comunicação criadas, proporcionando oportunidades para entrarem em contato com o mercado de trabalho. Conclusão: O processo de gestão do conhecimento se materializou assim que as interações promoveram reflexões sobre o próprio "eu", e foi possível perceber que a gestão do conhecimento é uma relação de ensinar-aprender e coexistência entre todos os atores do processo de ensino.
\end{abstract}

Palavras-chave: Gestão do conhecimento; Agências de comunicação; Ensino superior; Comunicação; Aprendizagem Baseada em Projetos.

\begin{abstract}
Introduction: In the current scenario of higher education in the area of Communication, it is necessary to have an education that expands the capacity to meet the demands of the market. There is a growing need to combine theory and practice in teaching, and with that, the understanding of teamwork and the knowledge of the dynamics of the performance of communication agencies. The objective of this study is to understand how the use of active methodologies can create spaces for knowledge management and thus contribute to the learning of the profession in the disciplinary context in Communication courses. Method: Develops a descriptive qualitative research applied in classes in which the author taught in undergraduate courses in the area of Communication with the use of Project-based Learning methodology and the model of Five phase of the knowledge creation process. In the classroom, a dynamic of formation of communication agencies by groups of undergraduate students was applied in the period from 2014 to 2019. Results: The change from the traditional method to the proposed knowledge management process generated insecurity and an effort of interlocution by the students, demanding maturity, and a position of greater autonomy. The communication agencies set up by the students presented their identity and the communication pieces created, providing opportunities to get in touch with the job market. Conclusions: The knowledge management process materialized as soon as the interactions promoted reflections about the "I" itself, and it was possible to realize that knowledge management is a teaching-learning relationship and coexistence between all the actors in the teaching process.
\end{abstract}

Keywords: Knowledge management; Communication agencies; Higher education; Communication. Project-Based Learning.

\section{INTRODUÇÃO}

O ensino superior na área de Comunicação se desenvolve a partir das exigências de novos tempos, de uma rede teórica, um esforço intelectual das associações de classe, profissionais da área, diretrizes curriculares do Ministério da Educação (MEC), que se desdobram para inserir no mercado um profissional preparado para a atividade estratégica de comunicação com os diferentes públicos. Yanaze (2007) destaca que a qualidade da rede de relacionamentos de uma organização pode determinar o seu sucesso ou fracasso, e a comunicação tem papel decisivo e ativo na gestão desta, pois busca o envolvimento e o comprometimento dos públicos, o que é indispensável para atingir os objetivos organizacionais: ganhar confiança, reputação, identidade e valoração à marca. Por isso, aparece e se amplia a necessidade de aliar a teoria à prática no ensino em cursos de Comunicação, para refletir as mudanças com que as organizações se deparam no século XXI, de ordem mercadológica - ligada ao consumo e a competitividade; de ordem ética - relacionada à transparência; de ordem social - no que tange as legitimidades das organizações; e de ordem comunicacional - no relacionamento das organizações com seus públicos de interesse. 
E como preparar o aluno universitário para atuar neste ambiente e administrar um processo tão abrangente de relacionamento? Envolvida com essa preocupação, a autora, que é professora em cursos de Comunicação, vem trabalhando metodologias ativas na condução de seu trabalho docente na área de Comunicação, que visa à formação de agências de comunicação entre estudantes dos cursos de Relações Públicas e Radialismo. Deste modo, o objetivo deste trabalho é compreender como o uso de metodologias ativas pode criar espaços para a gestão do conhecimento e, assim, contribuir para a aprendizagem da profissão no contexto disciplinar em cursos de Comunicação.

Nota-se que no cenário atual do ensino superior cresce a importância da compreensão do trabalho em equipe, e a gestão do conhecimento, proposta por Takeuchi e Nonaka (2008), auxilia teoricamente este processo, pois envolve o comprometimento pessoal, o indivíduo, o grupo e o ambiente em uma constante e dinâmica interação. Nesta perspectiva dialética, Takeuchi e Nonaka (2008) entendem que o conhecimento é paradoxal, pois envolve tanto o conhecimento tácito quanto o explícito, o corpo e a mente, o indivíduo e a organização; e nas organizações, a criação de conhecimento envolve habilidade de lidar com os opostos, cultivá-los e utilizá-los para encontrar o melhor caminho. De acordo com os autores, criar novos conhecimentos significa recriar atividades a todos os envolvidos em um processo permanente de renovação pessoal, para atingir um ideal que seja agregador e universalizante. Ao gerar conhecimento, é preciso identificar, selecionar e escolher como aplicá-lo de forma estratégica. A exemplo disso, Takeuchi e Nonaka (2008) e Terra (2000) esclarecem que o conhecimento pode ser organizado em duas dimensões:

a) conhecimento tácito: conjunto de habilidades que se desenvolvem no plano da dimensão cognitiva, construídas pela experiência e pelas experimentações pessoais, com difícil articulação por envolverem modelos mentais, crenças e perspectivas incorporadas na formação identitária dos atores sociais, que moldam a percepção de mundo;

b) conhecimento explícito: aquele que pode ser formalizado, sistematizado e facilmente comunicável, capaz de transformar o conhecimento tácito (individualizado) em explícito (coletivo).

Takeuchi e Nonaka (2008) acreditam que o conhecimento é criado apenas pelos indivíduos, todavia, pode-se transformar em conhecimento para a organização como um todo. Portanto, na perspectiva dialética, que aceita o que aparenta estar nas extremidades opostas como interdependentes e complementares, a gestão do conhecimento na formação profissional busca superar a dicotomia entre a teoria e a prática, entendendo a sua indissociabilidade. Ainda, conforme os autores, "a criação do conhecimento está ancorada no pressuposto crítico de que o conhecimento humano é criado e expandido através da interação social entre conhecimento tácito e conhecimento explícito" (Takeuchi \& Nonaka, 2008, p. 59).

Essa conversão é possível em uma constante e dinâmica interação entre esses conhecimentos, formada pela transferência entre quatros diferentes modos de conversão, que são conhecidos como SECI: socialização, externalização, combinação e internalização.

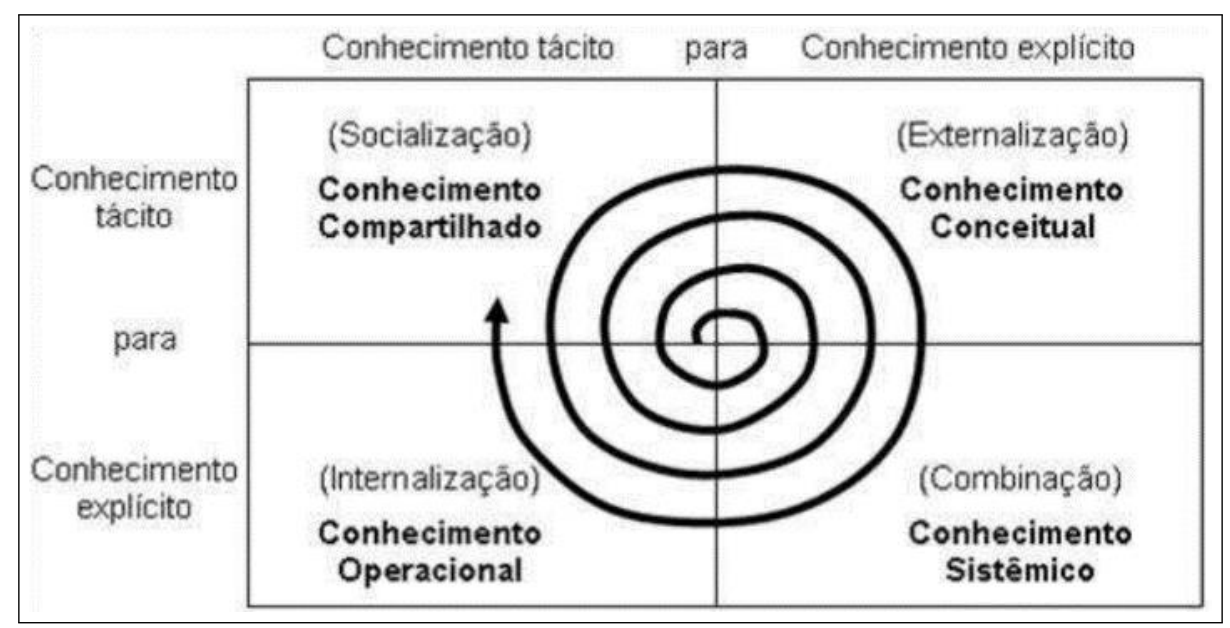

Figura 1. Modelo SECI

Fonte: Takeuchi e Nonaka (2008)

O primeiro modo de conversão do conhecimento é a socialização, que se inicia com a construção de um campo de interação, em que a troca de ideias e as percepções é facilitada pela socialização. Nos trabalhos em equipe, este momento pode ocorrer de forma intencional, por meio de reuniões em grupo, seminários e palestras, trocas de informações entre os participantes.

O segundo modo de conversão do conhecimento é a externalização, considerado o mais importante neste processo, uma vez que é nesse momento que se cria o conhecimento novo. Essa conversão é desencadeada pelo diálogo 
ou pela reflexão coletiva. É o conhecimento tácito, agora articulado aos conhecimentos explícitos, traduzidos e externalizados num outro conhecimento. Intercâmbio este que é facilitado pela metodologia aplicada neste estudo, na medida em que essa possibilita a inter-relação entre o conteúdo teórico específico disseminado aos alunos e se relaciona com a sua atuação como profissional em uma agência de comunicação experimental, mediado pela docente. A partir dessa fase, na qual o conhecimento tácito do indivíduo se articula com o conhecimento explícito - leituras, sites, vídeos e outras fontes - o aluno pode exteriorizá-lo, em trocas sinergéticas com outros colegas e a docente, com objetivo do debate, para trazer à tona as ambiguidades e dúvidas que suas reflexões podem gerar.

O terceiro modo de conversão do conhecimento é a combinação, no qual são sistematizados os conceitos em um sistema de conhecimento. Este processo "envolve a combinação de diferentes corpora de conhecimento explícito. Os indivíduos trocam e combinam o conhecimento através de meios como documentos, reuniões" (Takeuchi \& Nonaka, 2008, p. 65).

Finalmente, a quarta e última forma de conversão do conhecimento, a internalização, está intimamente ligada ao "aprender fazendo", na qual os outros tipos de conversão já vistos passam a coligar o patrimônio cognitivo do aluno. É quando ocorre a incorporação do conhecimento explícito em conhecimento tácito acumulado, e se concretiza na formação da agência, sua estrutura, departamentos e funções, a partir das experiências compartilhadas: a aprendizagem propriamente dita dos participantes da ação.

Existe a necessidade do aluno que estuda na área de Comunicação conhecer a dinâmica de atuação das agências de comunicação, com profissionais especializados para compreender e interpretar públicos e estabelecer diretrizes, políticas e estratégias de relacionamentos em programas eficazes que dão suporte aos negócios das organizações. Uma agência de comunicação é "uma empresa prestadora de serviços especializados em comunicação organizacional corporativa, envolvendo principalmente as áreas de: gestão estratégica, relações com a mídia, consultoria política, comunicação interna, organização de eventos e design e conteúdo" (Schaun \& Rizzo, 2009, p. 52).

Faz-se necessário que os estudantes tenham uma formação que amplie sua capacitação diante das exigências do mercado, para a solução de problemas práticos e ações de liderança e gestão, na busca de informações e de conhecimento. É nesse contexto que esse trabalho se circunscreve. Parte-se do pressuposto de que a importância das agências de comunicação cresce a cada dia, assim como o papel do profissional que atua nesse segmento. Desse modo, o objetivo da disciplina foi o de aplicar ações de metodologia ativa para a formação de agências de comunicação no ensino de Comunicação, assim como discutir a importância de um processo de intercâmbio - teórico e prático - na formação profissional na graduação. A partir de intervenções de metodologias ativas utilizadas em sala de aula como estratégia de ensinar e aprender, o objetivo específico foi o de promover a gestão do conhecimento em sala, ao motivar os discentes, capacitando-os para intervir em contextos de incertezas e complexidades, como é o caso do processo de montagem de agências de comunicação, nas quais os alunos se organizam com a mediação do professor como se fossem agências autênticas constituídas formalmente.

Metodologias ativas apresentam como uma de suas principais características a inserção do estudante como agente principal do seu conhecimento, à medida que esse se compromete em seu processo educativo, devido a múltiplos fatores, tais como: rapidez na produção de conhecimento, a provisoriedade das verdades construídas no saber científico e, principalmente, na facilidade de acesso à vasta gama de informação, deixando de ser baseado na mera transmissão de conhecimentos (Berbel, 2011; Bzuneck e Guimarães, 2010).

Portanto, as metodologias ativas são uma orientação ao processo de ensinar e aprender que procura envolver a todos de maneira ativa, na busca da participação dos envolvidos, centrados na realidade em que estão inseridos. Diferentemente do modelo tradicional, as metodologias ativas de ensino e aprendizagem são um forte estímulo ao reconhecimento dos problemas do mundo atual (tanto nacional quanto regional), tornando os alunos capazes de intervir e promover as transformações necessárias. O aluno torna-se protagonista no processo de construção de seu conhecimento, sendo responsável pela sua trajetória e pelo alcance de seus objetivos, no qual deve ser capaz de autogerenciar e autogovernar seu processo de formação.

Nela o docente se torna mediador desse processo a partir de métodos e estratégias. Trata-se de uma forma de promover o aprendizado a partir de uma problemática que é escolhida para a exploração sob uma ou várias óticas disciplinares. Essa metodologia valoriza todos os sujeitos participantes, operacionalizando o conceito de aprendizagem significativa centrada no aluno, e não no conteúdo de modo estrito. Enfim, é um novo olhar, não apenas nos fundamentos da ciência e nos métodos da prática, mas nas relações da profissão com o público e com a sociedade.

A metodologia ativa escolhida foi a Aprendizagem Baseada em Projetos (ABP), que para Santos (2020, p. 125) "[...] é considerada uma abordagem capaz de desenvolver as habilidades relacionadas à resolução de problemas, explorando as experiências e os conhecimentos que os alunos trazem para a sala de aula e promovendo um ambiente cooperativo". Ainda, o estudante pode levantar dados, buscar informações, ler, conversar, anotar, calcular, enfim, reunir o necessário para converter em ponto de partida de um projeto. Desse modo:

[...] a ABP possibilita o trabalho em equipe, o estímulo da criticidade, a autonomia e o exercício da criatividade, já que trabalha com a solução de problemas em contextos relacionados ao cotidiano dos 
estudantes, ou seja, contextos fora da sala de aula. Sendo assim, pode envolver ações interdisciplinares capazes de se aproximarem da realidade social de cada aluno, fazendo com que se apropriem do objeto de estudo e apliquem o conhecimento. (Cordeiro, Leão, \& Couto, 2021, p. 4).

No processo de formação profissional na graduação, é vital a articulação entre teoria e prática no atual contexto social. Nesse aspecto, este trabalho tem dois âmbitos de atuação: o da práxis pedagógica e o da práxis profissional. Enquanto práxis pedagógica, esta dimensão se refere à missão da universidade em compartilhar e socializar conhecimento, orientando-se por novas formas de conhecimento, pautadas em complexas e novas maneiras de compreender e entender o mundo, o que pressupõe ações inovadoras que fundamentem a prática do docente. Quanto à práxis profissional, é voltada à teoria e prática sobre formação de agências de comunicação, com uso da Aprendizagem Baseada em Projetos, para que os alunos desenvolvam capacidades de trabalho em grupo e construam conhecimento ao formar sua própria agência, o projeto propriamente dito.

\section{MÉTODO}

Trata-se de uma pesquisa descritiva de caráter qualitativo, aplicada nas turmas em que a autora lecionou, em cursos de graduação da área de Comunicação, no período de 2014 a 2019. Cada disciplina tem duração semestral, conta com quatro créditos, que completam 60 horas, entre exposição de conteúdo, orientações específicas e atividades supervisionadas para a execução do projeto, que deve ser desenvolvido por equipes com vistas a contemplar as diferentes áreas de comunicação que compõe uma agência. As metodologias ativas utilizadas centraram-se no aprender fazendo, com uso da Aprendizagem Baseada em Projetos e do modelo de Cinco Fases do Processo de Criação de Conhecimento de Nonaka e Takeuchi (1997). A sala de aula, segundo Cordeiro et al. (2021, p. 4):

A sala de aula é um ambiente em que os professores podem testar metodologias que melhor se adaptem à sua realidade, assim como adequar e reinventar novas possibilidades, sempre com o objetivo de aprimorar sua prática docente e corroborar o processo de construção do conhecimento de seus estudantes.

A ação metodológica em sala de aula foi orientada em função do projeto de formação de agências de comunicação em grupos de alunos da graduação, na qual o professor como mediador elucida a natureza do projeto aos participantes numa abordagem teórica e prática, desenvolvendo com o grupo as dimensões dos problemas designados pelo tema.

Para guiar o caminho metodológico e proceder à análise dos resultados, foi aplicado o Modelo de Cinco Fases do Processo de Criação de Conhecimento de Nonaka e Takeuchi (1997), que demonstra a interação entre o conhecimento tácito e o explícito em condições que promovam o conhecimento organizacional: Compartilhamento do conhecimento tácito, criação e justificação de conceitos, construção de arquétipos e difusão interativa de conhecimento.

1) Compartilhamento do conhecimento tácito: nessa fase é possível estabelecer uma relação com o modo de socialização, pois o compartilhamento acontece entre pessoas com histórias diversas, distintos pontos de vista e motivações, sendo uma etapa crucial para a criação de conhecimento. A fim de que o compartilhamento ocorra na prática, é preciso um espaço em que as pessoas se relacionem umas com as outras, via diálogo e compartilhamento de experiências. Esse momento inicial foi realizado em sala de aula, com a apresentação da disciplina, explicação do projeto do semestre - a formação de agências - e a formação de grupos;

2) Criação de conceitos: corresponde à externalização, pois o conhecimento tácito passa pela verbalização em palavras e frases, para finalmente, cristalizar-se em conceitos explícitos. Esse processo se deu por uso de estratégias de raciocínio e uso de analogias, tais como pedir aos alunos que, no projeto de criação de sua agência, usassem metáforas e analogias, tais como imaginar que a agência fosse um animal ou uma fruta, qual seria e as suas características;

3) Justificação de conceitos: parte do princípio de discutir se os conceitos recém-criados fazem sentido à organização e à sociedade; assemelha-se a uma filtragem em que se reflete se os conceitos gerados fazem sentido socialmente. No caso da formação de agência, se a missão, visão, valores elaborados pelo grupo são importantes para eles e se, ao mesmo tempo, têm algum impacto social positivo na comunidade;

4) Construção de um Arquétipo: ocorre quando o conceito justificado é transformado em algo tangível ou concreto, e no trabalho com os alunos, se materializa com a criação da agência propriamente dita, quando essa é elaborada ao fim do projeto com seus membros constituídos em diferentes funções, com um nome/marca, missão, visão, valores e propósito social. Essa fase se assemelha à combinação;

5) Difusão Interativa do Conhecimento: assim que o novo conhecimento é criado, justificado e transformado em modelo, se passa para um novo ciclo de criação de conhecimento, entre organizações. É quando o compartilhamento de informações ajuda as pessoas a se situarem melhor no contexto da atividade, permeado por um processo contínuo de aprendizagem. Ao final do projeto, os alunos organizados em 
agências realizam uma apresentação do resultado de seu trabalho em equipe e, em grupos, trocam opiniões, compartilham informações e constroem um conhecimento coletivo acerca da experiência vivenciada e aprendida.

Os alunos formam suas agências a partir do trabalho em equipe e reuniões de briefing em sala de aula e, sob orientação da docente, definem estratégias de naming, objetivos e posicionamento da agência, os papéis e funções de cada membro, a elaboração da missão, visão e valores, estabelecimento de programa de comunicação (marca e identidade visual), cronograma de trabalho e levantamento de significados incorporados pelos participantes no processo.

Para a definição do naming, por exemplo, pedimos aos estudantes que escolham um elemento da natureza como uma fruta ou animal como símbolo da agência e justifiquem o porquê da escolha a partir de suas características e simbologia, em consulta a dicionários de significados e sinônimos e em sites de internet.

Na seção de resultados, são apresentados e analisados os dados e informações referentes à metodologia $\mathrm{ABP}$ aplicada em sala pela autora nos grupos formados por estudantes. As categorias de análise utilizadas são as cinco fases do processo de criação de conhecimento de Nonaka e Takeuchi (1997).

\section{RESULTADOS}

O processo de ensinar-aprender no ensino superior se transforma rapidamente e se volta cada vez mais ao aprender fazendo, lançando mão, para isso, de metodologias de trabalhos em equipe, voltadas à solução de problemas, com uso de dinâmicas, elaboração de mapas, projetos, trabalhos de pesquisa que ajudem o aluno em sua formação tanto do espírito científico como de boas práticas acadêmicas para a formação profissional. É dessa maneira que a metodologia ativa pode promover a autonomia, quando incentiva a criatividade e encoraja a procura pelo inusual, favorecendo o incremento do saber, e como efeito, do conhecimento individual e coletivo (Berbel, 2011).

Cabe lembrar que quando a atenção está centralizada nas teorias da aprendizagem e do desenvolvimento que priorizam os enfoques das ciências naturais positivistas, o fenômeno da educação não se completa, pois perde de vista questões essenciais referentes à maneira do homem estar-no-mundo, sua experiência com o mundo e as relações entre vontades, intencionalidade e cognição. Como diz Buarque (1991, não paginado):

A universidade tem um único papel social: gerar saber. Para cumprir seu papel social, a universidade tem que se adiantar. Realizar uma reforma na sua estrutura, no seu conteúdo e na sua prática de ensino. Mas sem perder de vista seu compromisso específico de servir ao social, mediante o saber que gera.

No sentido de poder privilegiar a responsabilidade social da educação superior, produzindo e socializando conhecimentos, não somente de mérito científico, mas também de valor social e formativo, importantes para o desenvolvimento econômico e para a cidadania pública: formando um profissional que priorize a ética e o bem-estar da coletividade.

Os espaços em que os futuros profissionais da comunicação irão atuar estão potencializados pelo avanço das novas tecnologias e pela percepção do mundo vivo como uma rede de relações dinâmicas em constante transformação, daí as necessidades de mudanças urgentes no ensino superior, visando, entre outros aspectos, às mudanças no ensinar e aprender.

As disciplinas ministradas pela docente nos cursos da área de Comunicação, mais especificamente, cursos de Relações Públicas e Radialismo, envolvem temáticas de Gestão da informação e da Comunicação de marketing, contempla desde ferramentas introdutórias, de formatação da agência de comunicação, auditoria e pesquisas de opinião, gestão da informação, montagem das agências, até as técnicas e estratégias de busca de informações, planejamento e execução das peças de comunicação requeridas na elaboração de uma identidade para a agência e na apresentação desta ao fim do semestre. Essas foram as disciplinas em que a metodologia de Aprendizagem Baseada em Projetos foi aplicada para o ensino da formação de agências de comunicação em grupos de alunos.

A formação de agências começa a partir de encontros em aulas que agrupam os implicados na situação estudada. As aulas centralizam as informações e oferecem interpretações e diálogo entre os envolvidos, proporcionando um espaço de gestão do conhecimento. A gestão do conhecimento depende do fator humano e da utilização do conhecimento em ações estratégicas, criando espaços criativos na e sobre a organização, desenvolvendo habilidades para compartilhamento, mediação e uso do conhecimento (Valentim, 2008). Os resultados do processo de aplicação da ABP e da criação de espaços de gestão do conhecimento na disciplina são sintetizados e descritos via Modelo de Cinco de Fases, a seguir:

Na fase 1, compartilhamento do conhecimento tácito, após a apresentação do projeto do semestre - a formação da agência - os alunos iniciam a composição da equipe e discutem as possíveis funções, trocando conhecimentos e expondo sua expectativa em relação ao trabalho. É um momento de exposição do conteúdo, mas também dos 
alunos se conhecerem, de pesquisarem juntos sobre o tema e formarem a equipe. Refere-se ao primeiro estágio da disciplina e envolve a apresentação do programa, conteúdo e sua implementação. É entendido como um processo de informação e de discussão para suscitar nas pessoas sentimentos e interesses antes não percebidos. E, também, levá-las a se motivarem para o semestre, que até então, não conheciam. Entre as atividades e ações dessa etapa estão: a) a formação da equipe; b) reuniões de briefing; c) a definição do papel e função de cada um dos membros. Quanto a esta última, a docente orienta os alunos a realizarem a proposta apresentada: constituir uma agência de comunicação com cinco a seis membros em diferentes funções: atendimento, planejamento, criação, mídia e produção.

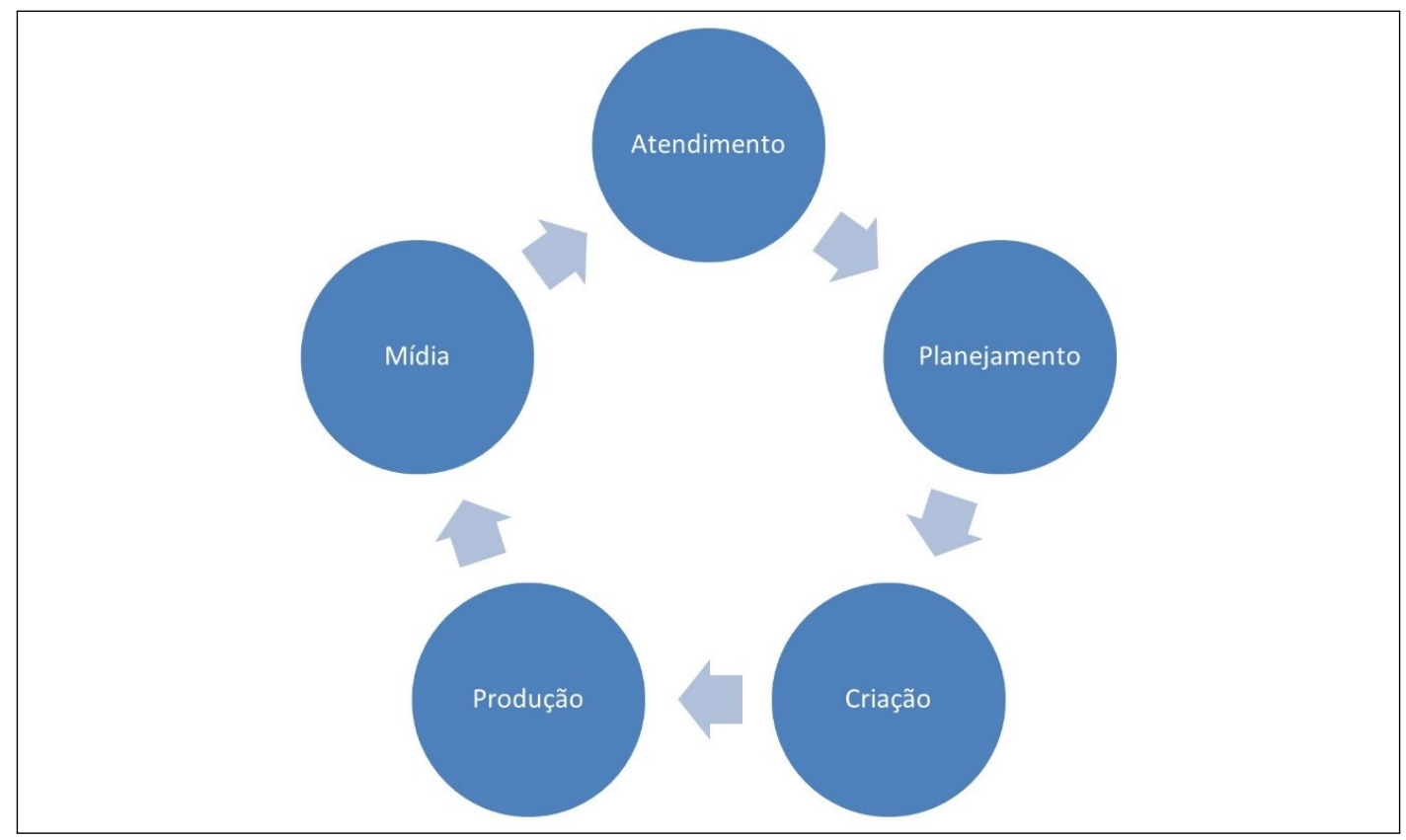

Figura 2. Funções em uma agência de comunicação Fonte: Lupetti (2012)

Esse é chamado um modelo de agência completa, ou full service, com todas as funções estruturadas, contudo, apresentamos em sala outros tipos de agências, as chamadas especializadas, específicas de uma área da Comunicação e que são cada vez mais enxutas, segmentando em partes e possibilitando que novas perspectivas de trabalho surjam, reforçando um amplo leque de atuação do comunicador. Em sala, nas primeiras aulas foi apresentado aos alunos o conteúdo sobre o que é uma agência de comunicação, sua estrutura, papéis dos membros, funções e o mercado de agências no Brasil. O objetivo foi o de discutir conceitos básicos e apresentar diretrizes para a formação de agências e suas especificidades.

Na fase 2, criação de conceitos, se iniciam os primeiros exercícios sobre naming, quando antes de elaborar as bases do que virá a ser uma agência, os alunos verbalizam em palavras e frases os seus valores, o que acreditam, usam metáforas e analogias que depois irão cristalizar-se em conceitos explícitos e na definição de identidade visual da agência. Um dos grupos de Radialismo, ao escolher como símbolo da agência o animal pavão, encontrou em seu sentido figurado uma estratégia e um insight para a definição do nome da agência, "pessoa extremamente vaidosa", buscando, a partir desta definição, pensar numa característica positiva do animal a partir de sua renovação, na primavera as penas do pavão se renovam. Por isso, essa ave é símbolo de renovação, imortalidade e renascimento para muitas culturas. Ao pesquisarem que "as penas do pavão simbolizam imortalidade, triunfo

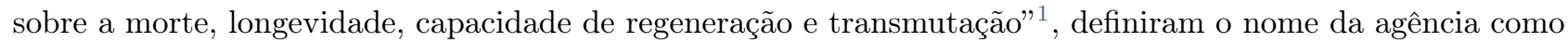
Triunfo, simbolizando a realeza, a prosperidade, sentidos elevados para a energia que o pavão transmite.

\footnotetext{
${ }^{1}$ Definição encontrada no site $\mathrm{Eu}$ Sem Fronteiras, no artigo $\mathrm{O}$ simbolismo do pavão. Recuperado de https://www.eusemfronteiras.com.br/o-simbolismo-do-pavao/
} 


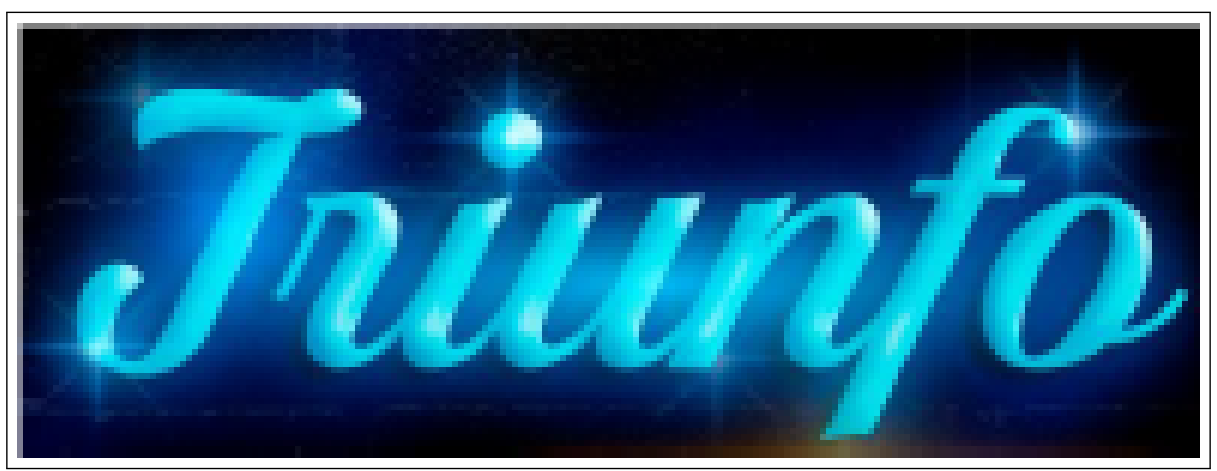

Figura 3. Logotipo da agência

Fonte: Trabalho dos alunos (2016)

Outra agência buscou inspiração em uma fruta para a escolha do nome: Mirtilo, um subarbusto que produz um fruto doce, azulado, utilizado para produção de tortas e geleias. Na justificativa apresentada pelos alunos, assim como a fruta, a agência é "recheada de coisas boas":

Essa fruta representa o conceito de "irreverência" de forma direta para nosso destaque no mercado. Somos uma Agência moderna que reconhece as suas raízes e o passado. Assim como o Mirtilo, contamos com profissionais ainda não tão populares, entretanto, somos riquíssimos em nutrientes, ideias e vontade para atender da melhor maneira as necessidades de nossos clientes. Nossa visão é ser uma Agência de Comunicação reconhecida na criação de ideias de sucesso (anotações de alunos, 2015).

Em seguida, na fase 3, a de justificação de conceitos, os grupos discutem se o nome recém-criado faz sentido para eles como uma organização e também à sociedade; é um processo de filtragem em que se constrói também a missão, visão e valores elaborados pelo grupo. A agência Mirtilo utilizou o sentimento de nostalgia, para buscar como diferencial um relacionamento próximo ao cliente em convergência com as demandas contemporâneas, explorando o posicionamento de que as ações de hoje criam as raízes do amanhã.

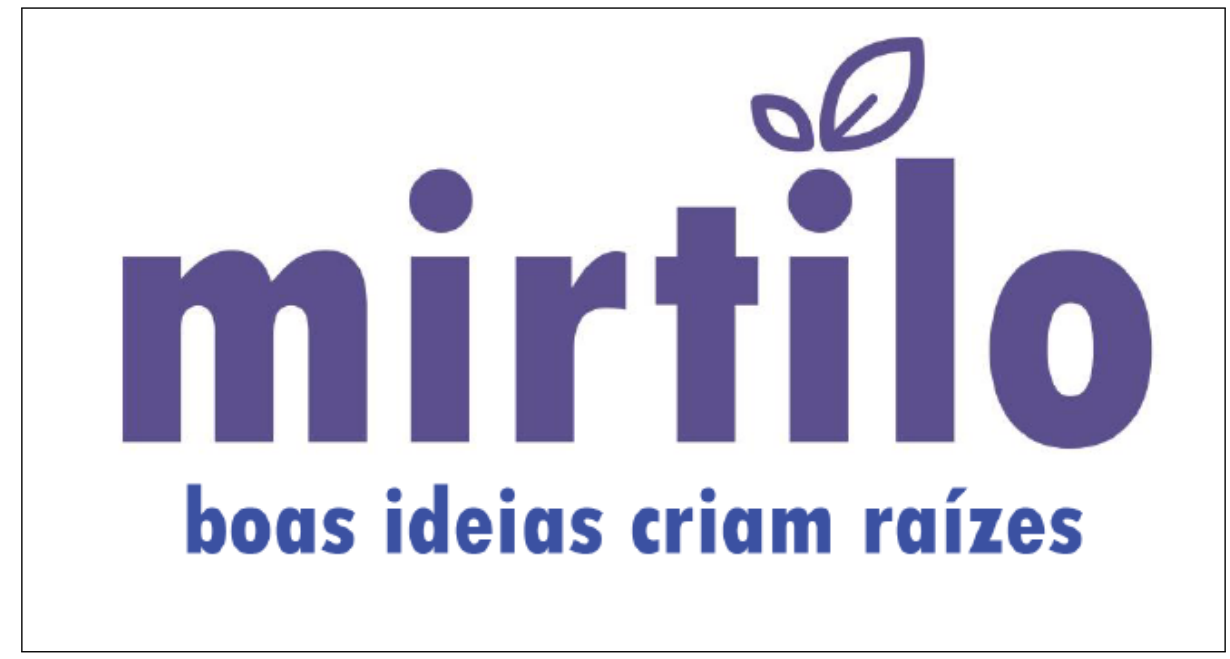

Figura 4. Logomarca e slogan Agência Mirtilo Fonte: Trabalho dos alunos (2015)

Na fase 4, construção de um arquétipo, após as definições conceituais, as ações de criação e produção de peças de divulgação para a agência e a elaboração de um planejamento da apresentação da agência são realizadas nesta etapa.

E por fim, na fase 5, difusão interativa do conhecimento, após o semestre de trabalho, as agências de comunicação montadas pelos alunos apresentam o planejamento e as peças de comunicação criadas por eles, expõem a missão, visão e valores construídos e debatem entre si. Nesta etapa se concretiza a apresentação das agências, com a exposição de sua finalidade e objetivos, da equipe, de sua identidade visual e das peças elaboradas, compostas por papelaria, cartão de visita, mídias sociais e storyboard (roteiro) de vídeo institucional. É uma aula final de apresentação cujos objetivos são: proporcionar um espaço para socializar e divulgar as agências efetivadas pelos estudantes; demonstrar, refletir e integrar estudantes e docente sobre a eficácia da metodologia ativa no processo de aprendizagem; ampliar o conhecimento dos alunos sobre a importância da comunicação estratégica na área; avaliar a qualidade do trabalho realizado a partir de suas apresentações durante a aula. 
Cena 2 - SALA DE JANTAR DA AVÓ / DIA (FLASHBACK)

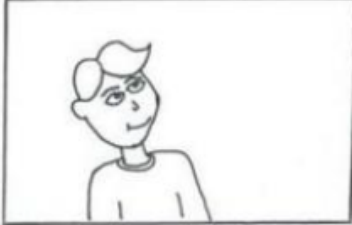

Plano Próximo do menino sentado à mesa. Ele olha para cima.

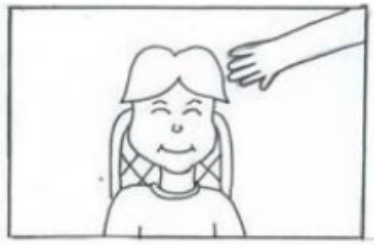

Plano Fechado do menino sentindo o cheiro da torta.

(Cross Fade para a próxima cena)

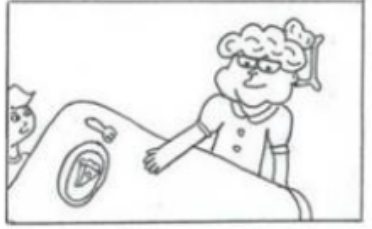

Plano Médio da avó colocando a fatia de torta sobre a mesa.

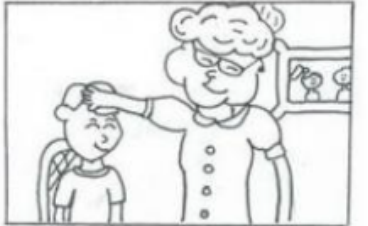

Plano Conjunto da avó fazendo cafuné no neto.

Figura 5. Storyboard de vídeo institucional da agência Fonte: Trabalho dos alunos (2015)

A partir do diálogo entre docentes e alunos, se resolveram as dificuldades, e no caso específico, se planejaram as ações para a apresentação final. De fato, como se observa, a mencionada iniciativa reconhece a importância do debate, como um campo de interação, para a sensibilização e compreensão dos conflitos organizacionais atuais, já estas não conhecem fronteiras e requerem uma gestão integrada de talentos, visão estratégica e criatividade.

Ensinar e aprender devem estar sempre articulados entre si e acontecem quando o estudante é capaz de apropriarse de conceitos científicos, incorporando processos de pensamento e vice-versa, ou quando consegue configurar o pensamento teórico, a partir de ações mentais na solução de problemas reais.

Em termos de metodologia, a disciplina oferece suporte conceitual e técnico, além de apresentar problemas específicos e situações concretas para a resolução, ou ainda, possibilitar o uso da gestão do conhecimento com a elaboração de mapas mentais para lidar na prática, com situações e dilemas do mercado.

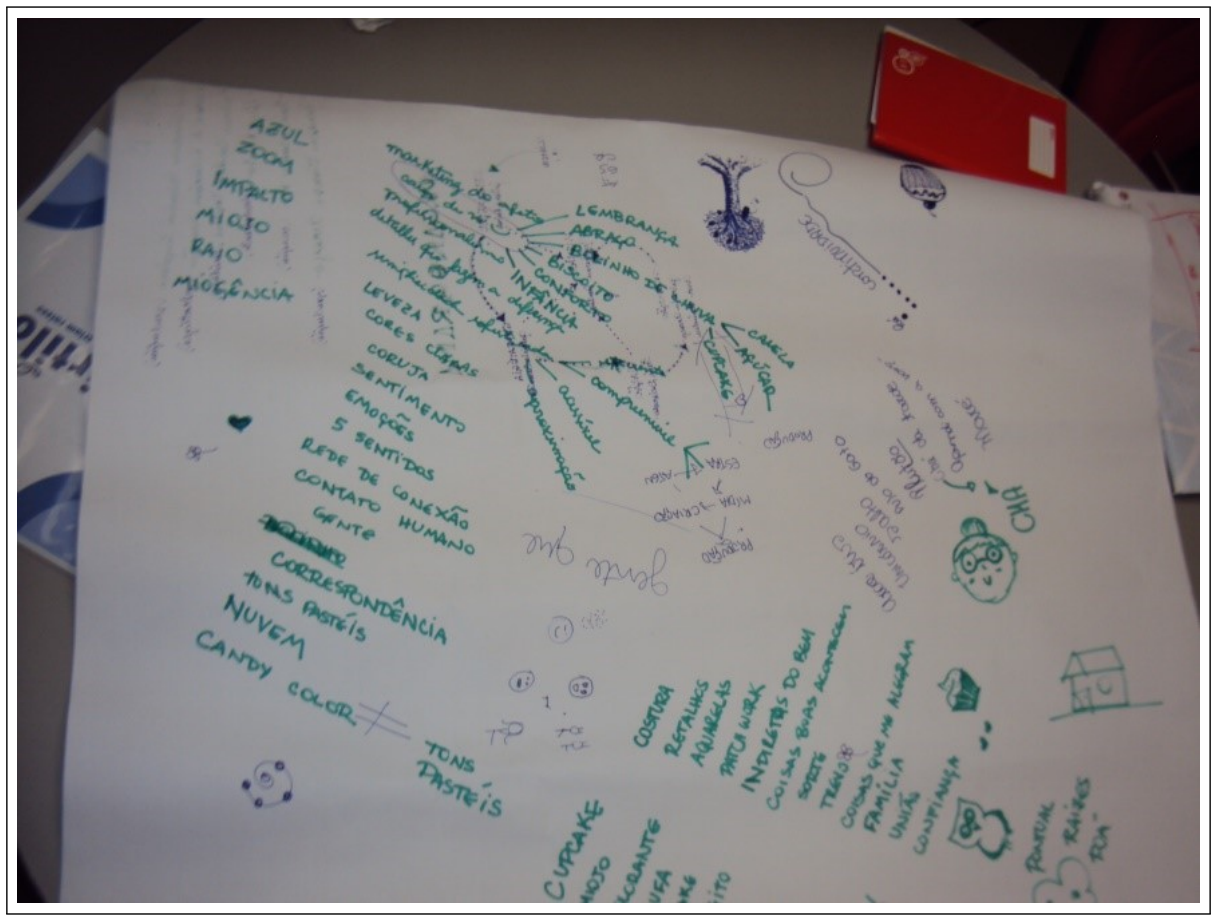

Figura 6. Mapa mental elaborado por alunos em sala de aula Fonte: Própria (2018) 
Os mapas mentais procuram representar, em detalhes, as informações que a equipe possui, mas que normalmente estão fragmentadas, difusas ou pulverizadas no processo da formação de agência. Serve como um instrumento para organizar o conhecimento do grupo, ilustrar ideias e conceitos, dar-lhes forma e contexto, traçar relacionamentos.

São utilizados para auxiliar a ordenação, construção de relações significativas e, em alguns casos, para a sequência de ações, é um processo dinâmico em que o conhecimento vai sendo construído (Belluzzo, 2007). Por proporcionarem e efetivarem o processo de criação e a construção de conhecimento, revelam decisões que podem ser tomadas pelo grupo num processo de gestão do conhecimento partilhado entre os membros da equipe. Deste modo, esta atividade de metodologia ativa utiliza a criação de mapas como forma de planejar ações e estratégias para alcançar objetivos específicos.

O cronograma de atividades e o conteúdo programático do curso são elaborados de forma a promover as interações entre os segmentos (docentes, discentes e mercado), possibilitando a criação de conteúdos, a aprendizagem, o ensino e a socialização.

Na disciplina via ABP, são criados espaços para a gestão do conhecimento, por exemplo, quanto à explicitação de conhecimentos, envolve a participação de profissionais do mercado que são chamados para uma palestra e bate papo sobre temas que envolvem o projeto da agência de comunicação e, assim, compartilham seus conhecimentos tácitos que se tornam explícitos em processos e produtos que realizam na rotina profissional em uma agência, no relacionamento com os clientes, na organização da própria estrutura da agência, na exposição e entendimento da composição dos diversos tipos de agências, além de experiências marcantes da prática profissional. O fato de que a interação entre os alunos (participantes do processo) e os profissionais garante a inovação e combinação na troca de conhecimentos tácitos para explícitos auxilia a produção material (as peças de comunicação) e imaterial (repertório e gestão do conhecimento dos agentes envolvidos), que surgem da imersão e engajamento promovidos por esta intervenção. Na disciplina, as experiências e vivências do aluno, o seu conhecimento tácito são compartilhadas com outros colegas por meio de reuniões em grupo, e segundo o modelo de Cinco Fases (Nonaka \& Takeuchi, 1997)(, atuam como um campo de interação para que as trocas ocorram, com orientações com o docente, profissionais, desenvolvendo novos estágios de cognição sobre a atividade: a auto-organização de uma agência de comunicação.

O processo de gestão do conhecimento desenvolvido na disciplina propõe uma mudança do método tradicional para este novo processo e faz com que os estudantes, num primeiro momento, se sintam desafiados na busca por conhecimento, gerando certa insegurança de como proceder e exigindo um grande esforço de interlocução. Essa mudança requer muita maturidade por parte dos estudantes e de todos os envolvidos, produzindo uma transformação no papel dos atores e convidando-os a uma posição de maior autonomia na sua própria formação.

Ao final da disciplina, os alunos produzem um pequeno texto, refletindo sobre o processo de conhecimento ao longo do semestre. Nesta atividade, se pede um texto de até 10 linhas sobre o processo de formação de agência durante a disciplina. Como sugestão, se apresentam questões-guia para a produção textual do grupo que envolvem a produção do conhecimento, a socialização, externalização, combinação e internalização: 1) Vocês já tinham conhecimento sobre conteúdos do que é uma agência de comunicação e suas formas de comunicação? Como foi a formação do grupo, se vocês já se conheciam; como foram as aulas, as reuniões e a troca de conhecimento entre vocês; 2) Como foi o debate entre vocês sobre as tarefas passadas, principalmente para a escolha do nome e marca da agência e funções dos membros; 3) Como foi a divisão de tarefas entre os membros e como foi o processo de lidar com organização e tempo das reuniões etc.; 4) E, por fim, como foi a experiência de ver a agência formada, com sua estrutura, identidade visual, departamentos e funções, a partir de experiências compartilhadas na disciplina. Segue um exemplo de texto de uma das agências formadas na disciplina:

O processo de formação da Agência B Side foi uma experiência única para todos nós. Os membros já possuíam uma boa ideia do que é e o que faz uma agência de comunicação, mas as tutorias e reuniões da própria agência aprofundaram muito bem o assunto. A divisão de tarefas funcionou da melhor forma possível e embora todos os integrantes trabalhem ou participem de algum projeto de extensão, isso não afetou no desenvolvimento das atividades, já que a sintonia foi muito boa e todos buscaram sempre reservar o tempo necessário à agência. A maioria de nós já se conhecia, mas mesmo entre aqueles que não, houve grande entrosamento desde a primeira reunião. E hoje olhamos para a B Side com sua marca, slogan, texto corporativo e projetos idealizados e sentimos um gigantesco orgulho, porque nela está a melhor parte de nós (anotações de alunos, 2016)

A reflexão crítica sobre a prática, os avanços, resistências e dificuldades também foram indispensáveis para preparar o aluno na tomada de decisões de forma autônoma e para o trabalho em grupo. Muitos grupos de disciplinas de cursos noturnos apontaram a dificuldade de se reunir com os colegas fora da sala de aula, por trabalharem durante o dia. Daí a importância da atuação e orientação docente para estimular a equipe no melhor uso possível do tempo em sala de aula. Outras questões surgiram, referentes à dificuldade em dividir ou assumir tarefas ao longo do semestre. De fato, são estes aspectos que enfrentarão no mercado de trabalho real. Vale reforçar que a natureza efetiva do ensino implica em promover a noção da autonomia do indivíduo no processo de aprendizagem (Freire, 2011). 


\section{CONSIDERAÇÕES FINAIS}

Desse modo, entendemos que o uso de metodologias ativas amplia os relacionamentos dos envolvidos, criando uma network inicial, é um processo de aprendizagem que envolve leituras e pesquisas, interação, colaboração e criação de uma agência de comunicação.

Ao fim de um semestre de aula, as agências de comunicação montadas pelos alunos apresentam a sua identidade e as peças de comunicação criadas por eles. Na abordagem da metodologia ativa (Bastos, 2006; Berbel, 2011), o professor deve atuar como mediador, tutor, amparado por um modelo pedagógico que articule os diferentes conteúdos ou disciplinas, promovendo uma aprendizagem integral que contemple uma visão humanística, crítica e ética, proporcionando oportunidades para os estudantes entrarem em contato com o mercado e seus problemas de comunicação.

O papel do professor, orientador ou tutor passa a ser o sujeito que proporciona o ambiente da aprendizagem a partir de práticas ativas da inteligência, e não exclusivamente o elemento transmissor de informação. Também no âmbito do ensino profissionalizante, diferente das metodologias tradicionais, o uso da ABP tende a ações participativas e relacionadas à vivência de fato, com situações de aprendizagem representativas para a vida pessoal e profissional dos atores envolvidos. E ao garantir espaços de aprendizagem continuada para compreender, exercitar, avaliar e criticar a própria metodologia contribui com o processo de gestão do conhecimento, ao considerar a experiência, a busca de soluções e a aprendizagem em equipe construída em sala de aula e fora dela.

Na chamada Sociedade da Informação, em constante mudança, cabe destacar a importância do desenvolvimento de temas que discutam a gestão do conhecimento, que pressupõe uma reflexão aprofundada sobre o contexto atual do ensino-aprendizagem, especialmente no âmbito do ensino superior. De fato, como se observa, a mencionada iniciativa disciplinar reconhece a importância do uso de metodologias ativas para a gestão do conhecimento, a partir do compartilhamento, do incentivo ao trabalho em equipe, da compreensão de conflitos organizacionais, da difusão interativa de conhecimentos que requerem uma gestão integrada de talentos, visão estratégica e criatividade.

Nesse processo de formação de equipes, constituição de agências, elaboração de estratégias e identidade visual, que envolve independência, criatividade, habilidades e conhecimento, há um processo de gestão do conhecimento que se organiza em três momentos não lineares:

a) o da reflexão, que abrange a tomada de consciência do objeto da atividade por meio da motivação e da orientação do docente;;

b) o da análise, que se refere à formação de conceitos por meio das operações práticas desenvolvidas no processo de elaboração das peças da agência propriamente dita, além de aberturas para a capacitação no plano da linguagem, dos planejamentos e das operações em cada um dos momentos e etapas do processo;

c) o da capacidade de atuar internamente com os conceitos, ou seja, aprender a lidar com as teorias internalizadas aplicando-as no campo da Comunicação e na sociedade com vistas aos seus diferentes aspectos.

Dessa forma, a gestão do conhecimento se materializa na medida em que interagir com o outro e entender esse outro (equipes) propiciam reflexões sobre o próprio "eu", abrindo espaço para consolidar as identidades dos alunos e futuros profissionais: resultado das interações em sala de aula, entre os alunos e da dinâmica do processo de aprendizagem.

Neste processo de formação, Freire (2011) defende que o professor não é aquele que sabe tudo e que deve transferir conhecimento ao aluno, pelo contrário, para o educador não há práxis autêntica fora da unidade dialética da ação, pois a consciência não se transforma, a não ser na práxis, e o conhecimento não se transfere: se cria, a partir da ação sobre a realidade. O conhecer tem origem no agir. Sua proposta é a de que a educação seja dialógica, e em sua dinâmica o aluno se torne o centro do processo de conhecimento com a mediação do docente, num constante "aprender fazendo".

Então, resta destacar que a gestão do conhecimento é uma relação de ensinar-aprender e coexistência mútua, que envolve professores, alunos e organizações atuando em conjunto, não no sentido da transferência do conhecimento, mas sim de construção, negociação, tendo como objeto descobertas e interpretações sobre interesses comuns da aprendizagem e das expectativas coletivas da área de Comunicação. 


\section{REFERÊNCIAS}

Bastos, C. C. (2006). Metodologias ativas. Recuperado de http://educacaoemedicina.blogspot.com/2006/02/ metodologias-ativas.html

Belluzzo, R. C. B. (2007). Construção de mapas: desenvolvendo competências em informação e comunicação (2a. ed.). Bauru: Cá entre nós.

Berbel, N. A. N. (2011). As metodologias ativas e a promoção da autonomia de estudantes. Semina: Ciências sociais e humanas, 32(1), 25-40. doi: 10.5433/16790383.2011v32n1p25

Buarque, C. (1991). O papel social da universidade. In Notas para a conferência à plenária do conselho de reitores das universidades brasileiras. Campinas.

Bzuneck, J. A., \& Guimarães, S. E. R. (2010). A promoção da autonomia como estratégia motivacional na escola: uma análise uma análise teórica e empírica. In Motivação para aprender: aplicações no contexto educativo (p. 43-70). Petrópolis: Vozes.

Cordeiro, P. A. S., Leão, A. M. A. C., \& Couto, J. A. (2021). Ação pedagógica pautada numa abordagem híbrida à luz da aprendizagem baseada em projetos. Revista Docência do Ensino Superior, 11, 1-21. doi: 10.35699/22375864.2021.24721

Freire, P. (2011). Pedagogia da autonomia: saberes necessários à prática educativa (43a. ed.). São Paulo: Paz e Terra.

Lupetti, M. (2012). Gestão estratégica da comunicação mercadológica: planejamento.

Nonaka, I., \& Takeuchi, H. (1997). A criação de conhecimento na empresa. Rio de Janeiro: Campus.

Santos, A. C. M. Z. (2020). Contribuições da aprendizagem baseada em projetos: análise da utilização do método em disciplina do curso de administração. Revista Thema, 17(1), 124-134. doi: 10.15536/thema.V17.2020.124-134.1493

Schaun, A., \& Rizzo, E. (2009). Agências de comunicação: teoria e prática. São Paulo: Expressão e Arte Editora.

Takeuchi, H., \& Nonaka, I. (2008). Gestão do conhecimento. Porto Alegre: Bookman.

Terra, J. C. C. (2000). Gestão do conhecimento: o grande desafio empresarial. São Paulo: Negócio Editora.

Valentim, M. L. P. (2008). Informação e conhecimento em organizações complexas. In Gestão da informação e do conhecimento no âmbito da ciência da informação (p. 11-26). São Paulo: Cultura Acadêmica.

Yanaze, M. H. (2007). Gestão de marketing e comunicação: avanços e aplicações. São Paulo: Saraiva Educação SA.

Como citar este artigo (APA):

Guaraldo, T. S. B. (2022). Metodologias ativas como espaço de gestão do conhecimento: uma experiência no ensino superior em Comunicação. AtoZ: novas práticas em informação e conhecimento, 11,1-12. Recuperado de: http://dx.doi.org/10.5380/atoz.v11.80729 


\section{NOTAS DA OBRA E CONFORMIDADE COM A CIÊNCIA ABERTA}

\section{CONTRIBUIÇÃO DE AUTORIA}

\begin{tabular}{|l|c|}
\hline $\begin{array}{l}\text { Papéis } \\
\text { e contribuições }\end{array}$ & $\begin{array}{c}\text { Tamara de Souza } \\
\text { Brandão Guaraldo }\end{array}$ \\
\hline Concepção do manuscrito & X \\
\hline Escrita do manuscrito & X \\
\hline Metodologia & X \\
\hline Curadoria dos dados & X \\
\hline Discussão dos resultados & X \\
\hline Análise dos dados & X \\
\hline
\end{tabular}

\section{Disponibilidade de Dados Científicos da Pesquisa}

Os conteúdos subjacentes ao texto da pesquisa estão contidos no manuscrito.

\section{EQUIPE EDITORIAL}

\section{Editora/Editor Chefe}

Maria do Carmo Duarte Freitas (https://orcid.org/0000-0002-7046-6020)

\section{Editora/Editor Associada/Associado}

Paula Carina de Araújo (https://orcid.org/0000-0003-4608-752X)

Helza Ricarte Lanz (https://orcid.org/0000-0002-6739-2868)

\section{Editora/Editor de Texto Responsável}

Cristiane Sinimbu Sanchez (https://orcid.org/0000-0002-0247-3579)

Nicholle Ferreira Murmel Liali (https://orcid.org/0000-0002-1086-908X)

\section{Editora/Editor de Layout}

Felipe Lopes Roberto (https://orcid.org/0000-0001-5640-1573) 